ISSN: $2773-7349$

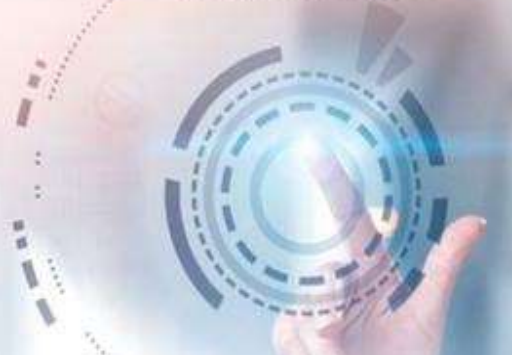

Sociedad \& Tecnología

Revista del Instituto Tecnológico Superior Jubones

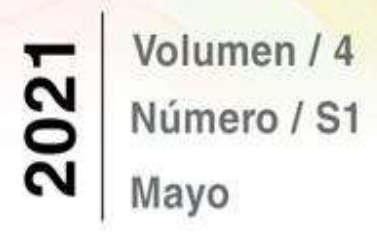

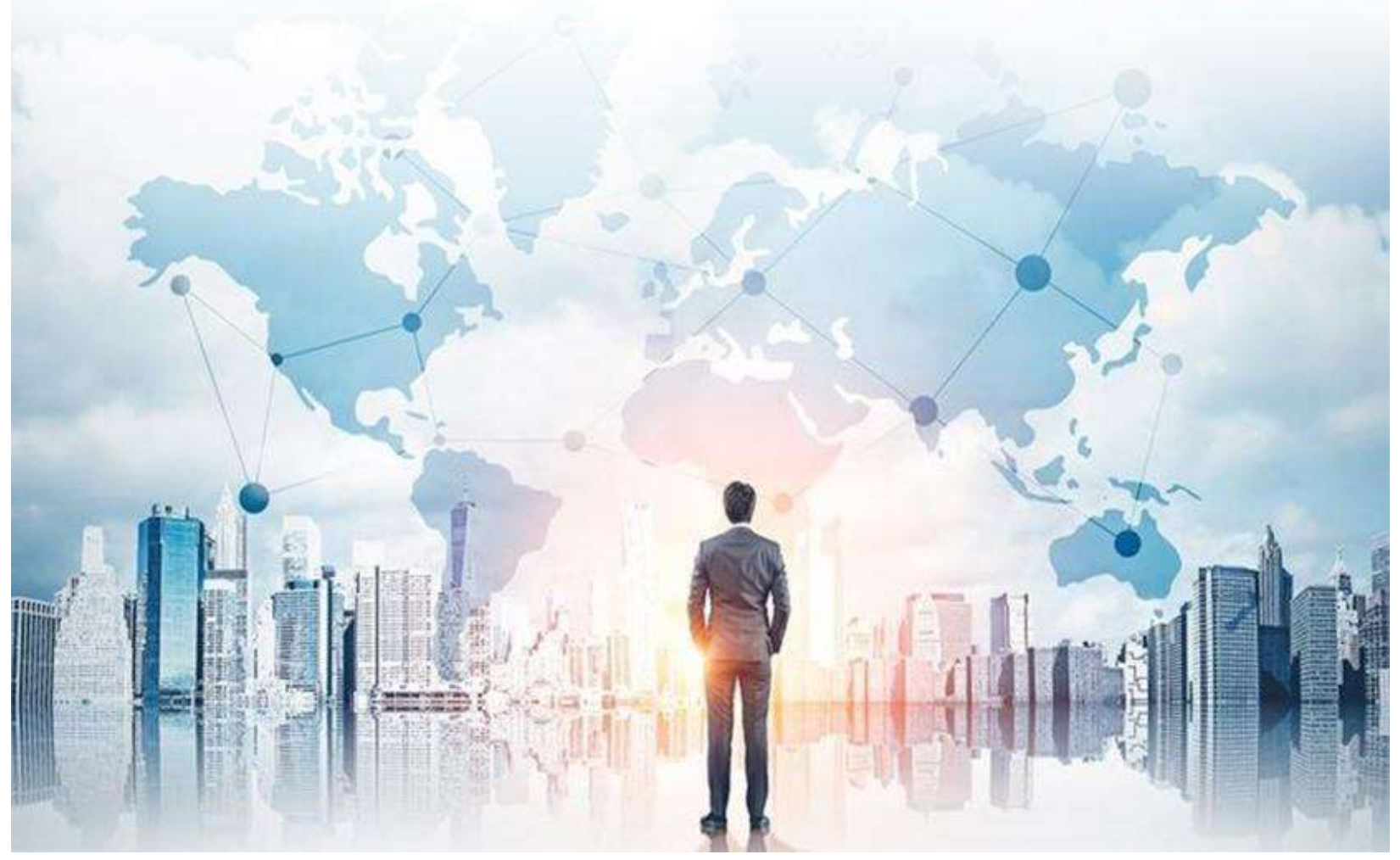




\section{El principio de favorabilidad frente a nuevos procedimientos del Código Orgánico Integral Penal}

The principle of favorability in the face of new procedures of the Comprehensive Penal Organic Code

Bolívar Enrique Figueroa Arévalo ${ }^{1}$

E-mail: bolfigue@yahoo.com

Orcid: https://orcid.org/0000-0002-5282-2001

Gabriel Yovany Suqui Romero²

E-mail: gsuqui@utmachala.edu.ec

Orcid: https://orcid.org/0000-0002-3704-8193

${ }^{1}$ Fiscalía Nacional del Ecuador, sede provincia de El Oro, maestrante de la Universidad Técnica de Machala, Machala, Ecuador.

2Profesor de Derecho Penal, carrera de Derecho de la Universidad Técnica de Machala, Machala, Ecuador.

\section{Cita sugerida (APA, séptima edición)}

Figueroa Arévalo, B. E., Suqui Romero, G. Y. (2021). El principio de favorabilidad frente a nuevos procedimientos del código orgánico integral penal. Revista Sociedad \& Tecnología, 4(S1), 240-255.

\section{RESUMEN}

El reconocimiento de los derechos humanos motivó la decisión internacional de proteger a los ciudadanos del uso desmedido del poder punitivo del Estado y con ello la necesidad de articular ciertas garantías y principios en pro de hacer efectiva dicha protección, entre estos el debido proceso y en especial el principio de favorabilidad. Este trabajo tiene como propósito determinar la vigencia del principio de favorabilidad frente a los nuevos procedimientos del Código Orgánico Integral Penal; el estudio se sustenta en los métodos analítico-sintético, hermenéutico, exegético, revisión documental, los materiales bibliográficos (ensayos, artículos científicos, tesis, libros, documentos normativos, etc.) se obtuvieron de diferentes fuentes electrónicas y físicas. Entre los principales hallazgos se encuentra el carácter convencional, constitucional y legal del principio de favorabilidad; su contenido sustantivo, procedimental y ejecutivo; y su condición retroactiva. Es un derecho humano fundamental que en Ecuador es considerado un principio autónomo e independiente del principio de legalidad. La divulgación de estos hallazgos permitirá la actualización de los conocimientos de los interesados en el tema.

\section{Palabras clave:}

favorabilidad, injuria calumniosa, procedimiento

\section{ABSTRACT}

The recognition of human rights motivated the international decision to protect citizens from the excessive use of the punitive power of the State and with it the need to articulate certain guarantees and 
principles in order to make said protection effective, including due process and especially the principle of favorability. The purpose of this work is to determine the validity of the principle of favorability in the face of the new procedures of the Comprehensive Organic Criminal Code; The study is based on analytical-synthetic, hermeneutic, exegetical, documentary review methods, bibliographic materials (essays, scientific articles, theses, books, normative documents, etc.) were obtained from different electronic and physical sources. Among the main findings is the conventional, constitutional and legal nature of the principle of favorability; its substantive, procedural and executive content; and its retroactive status. It is a fundamental human right that in Ecuador is considered an autonomous and independent principle of the principle of legality. The dissemination of these findings will allow the updating of the knowledge of those interested in the subject.

\section{Key words:}

favourability, libelous insult, procedure

\section{INTRODUCCIÓN}

Desde que el ser humano vive en sociedad, el Estado ha sido el encargado de establecer las normas de comportamiento para las personas, y ha dispuesto para sí el ejercicio del poder punitivo como forma de control de comportamiento de sus administrados (Ricoy \& Suárez, 2021). Por otra parte, el reconocimiento de los derechos humanos a nivel mundial motivó la decisión internacional de proteger a los ciudadanos de un uso desmedido de ese poder punitivo del Estado. Siendo, por un lado, el Derecho constitucional un derecho garantista por excelencia y, por otro lado, el Derecho penal, la herramienta más trasgresora de derechos que posee un Estado, de aquí la necesidad de establecer garantías y principios como el debido proceso y el principio de favorabilidad.
En este escenario, en algunas legislaciones la favorabilidad es un principio integrado al principio de legalidad, que de acuerdo a lo manifestado por González Navarro "debe producirse con las normas pre existentes al acto que se imputa, la favorabilidad permite que una norma penal al ser más benéfica al procesado 0 al delincuente puede aplicarse en forma retroactiva..." (2009, p. 23).

Esta favorable aplicación de preceptos jurídicos aplica tanto para el Derecho penal, el proceso penal, e inclusive la ejecución, como señala Pérez, citado por Hinojosa Gallo (2021), en el sentido que se debe buscar todo fundamento legal que permita la protección del procesado o sentenciado, en pro de tomar aquella decisión que sea menos restrictiva a los intereses de la persona procesada o con sentencia ejecutoriada.

Este principio, nacido a partir del aforismo jurídico de in dubio pro reo -lo más favorable para el reo- es reconocido en tratados y convenios internacionales, así como en las legislaciones nacionales (Carrión León, 2018), tanto con carácter constitucional como normativo legal, prevé que existe la posibilidad de aplicar una norma jurídica más benigna en aquellos casos en los que el ordenamiento sufra modificaciones, así como una dualidad de normas aplicables a un mismo caso, sea cuando una persona se encuentre frente a un proceso penal o cuando incluso haya sido sentenciada.

En Ecuador este principio goza de rango constitucional, de ahí su trascendencia e importancia. En efecto, la Constitución de la República del Ecuador (CRE) del 2008 en el artículo 76 numeral 5, señala que:

"en caso de conflicto de dos leyes de la misma materia que contemplen sanciones diferentes para un mismo hecho, se aplicará la menos rigurosa, aun cuando su promulgación sea posterior a la infracción. En caso de duda sobre una norma que contenga sanciones, se la aplicará en el sentido más favorable a la persona infractora" 
(Asamblea Nacional de la República del Ecuador, 2011).

Este principio o mandato constitucional es sistematizado normativamente en el Código Orgánico Integral Penal (COIP) dentro los denominados "Principios procesales", concretamente en el numeral 2 del art. 5, mismo que establece: "En caso de conflicto entre dos normas de la misma materia, que contemplen sanciones diferentes para un mismo hecho, se aplicará la menos rigurosa aun cuando su promulgación sea posterior a la infracción" (Asamblea Nacional de la República del Ecuador, 2014).

Por otra parte, respecto de las clases de procedimientos y de los delitos que los activan, con la entrada en vigencia en Ecuador del COIP en el año 2014, además de asomar nuevas figuras delictivas $y$ modificar otras, se establecen diferentes procedimientos con sus plazos y características. En este marco, la injuria no calumniosa migró desde el reconocimiento como delito, para pasar a ser tipificada como contravención, siéndole aplicable, por ende, otro tipo de procedimiento.

Este tema ha sido objeto de estudio por diferentes investigadores del ámbito nacional, entre ellos Jaramillo-Martínez (2016), Vásconez-Valdez (2016), BravoPardo (2017) e Hinojosa-Gallo (2021), quienes desde diversos enfoques $y$ metodologías estiman que a pesar que el principio de favorabilidad forma parte de los principios generales del sistema penal y ser una herramienta para proteger al ciudadano sometido a una investigación penal mediante la adopción de la pena más leve que afecte sus intereses ante la presencia de un conflicto de leyes, a partir de la expansión del derecho penal con el COIP en el año 2014 se ha desnaturalizado este principio, ocasionando la flexibilización de los límites del derecho penal y distorsionando en algunos casos su esencia, la protección del individuo y la salvaguarda de sus derechos fundamentales.
Tomando como referentes los resultados de estas investigaciones, el presente artículo parte de la necesidad de abordar académicamente un supuesto que a menudo se suele presentar en la praxis jurídico-penal. Para estos efectos se plantea el siguiente caso hipotético: contra A se instaura un delito de acción privada por el delito de injuria no calumniosa contemplado en una ley anterior; mientras se tramitaba el proceso de acción privada entró a regir una nueva ley penal, el COIP. En esta nueva ley, dejó de ser delito la injuria no calumniosa y pasó a ser contravención de una pena menor con un procedimiento diferente, el expedito contravencional. El COIP contiene una disposición transitoria primera que señala que cuando este en curso o trámite un proceso penal, actuaciones y procedimientos de investigación, éstas deben seguirse sustanciando conforme con el procedimiento penal anterior, es decir con el vigente en el Código de Procedimientos Penales (CPP), hasta su conclusión, pero que deberán acatarse las normas del debido proceso, cuando la sanción del delito esté relacionada en el COIP.

Frente a este supuesto, la reflexión académica de este trabajo gira en torno a que si en el caso de $A$, se debe aplicar el principio de favorabilidad procedimental; o en su defecto, si por observancia de la disposición transitoria primera del COIP, se debe desechar.

Para el análisis de esta situación hipotética se aborda como primera variable a la favorabilidad como principio independiente del principio de legalidad, al menos en la concepción penal ecuatoriana; $y$, como segunda variable a la injuria no calumniosa, revisando en primer lugar su tipificación y su procedimiento en la ley penal anterior $y$, en un segundo momento, su actual concepción como contravención en el COIP.

\section{Metodología}

Para la realización de esta investigación se tuvieron en cuenta los conocimientos 
adquiridos en la Maestría en Derecho y Justicia Constitucional, además de la revisión de bibliografías y documentos obtenidos de fuentes físicas y electrónicas. Muchos de los textos analizados fueron recuperados de ensayos, artículos científicos, documentos, libros, tesis situados en repositorios digitales, con el apoyo de las tecnologías de la información y las comunicaciones (TIC). Entre los documentos normativos internacionales analizados se destacan la Convención Americana sobre Derechos Humanos (1969), La Declaración Universal de los Derechos Humanos (1948) y El Pacto Internacional de Derechos Civiles y Políticos (1966). También, fueron consultados documentos normativos nacionales como la $\mathrm{CRE}$, el Código Penal (CP), el CPP y el COIP.

La información así obtenida fue examinada, interpretada, cotejada y sintetizada con el auxilio de los métodos analítico-sintético, hermenéutico, exegético y revisión documental. Una vez procesada la información y con el auxilio del programa EndNote se confeccionó una base de datos con 78 referencias bibliográficas, las que facilitaron la fundamentación teórica del trabajo y la construcción del discurso escrito.

La lógica indagatoria estuvo direccionada a la búsqueda de información de las siguientes temáticas:

- Antecedentes históricos del principio de favorabilidad.

- Desarrollo histórico del principio de favorabilidad en Ecuador.

- Noción del principio de favorabilidad.

- La favorabilidad como principio del debido proceso.

- Procedimiento de acción privada en el Código Penal y en el Código Orgánico Integral Penal (delitos de acción privada).

- Los procedimientos contravenciones.

- El delito de injurias calumniosas no graves.

- El principio de favorabilidad frente a la sustanciación de procedimientos diferentes.

\section{DESARROLLO}

Antes de adentrarnos en el análisis de la situación planteada es menester realizar una aproximación a los antecedentes, evaluación histórica y noción del principio de favorabilidad.

\section{Antecedentes históricos del principio de favorabilidad}

Algunos estudios consideran que el respeto a los derechos humanos se inició hace miles de años, debido a que existen evidencias en diferentes culturas como la mesopotámica, egipcia e india donde se manifestaba la preocupación por la protección y conservación de la vida y la existencia humana (Sánchez, 2018).

Sin embargo, el respeto y el progresivo ejercicio de los derechos humanos tienen su principal fundamento a partir de los sucesos acaecidos en la Segunda Guerra Mundial. En este contexto, la Organización de las Naciones Unidas (ONU) comprendió la necesidad que existía en aquellos días para determinar de forma clara y precisa el reconocimiento de estos derechos. La esencia de esto desemboca en la Declaración Universal de Derechos Humanos, la que procura el fiel cumplimiento por parte de los Estados firmantes, respetando así la dignidad humana como expresión máxima para la convivencia social no solo dentro de un país, sino a nivel mundial (Aldana \& Isea, 2018 y Tellez, 2020).

De este modo, en el contexto internacional, se erigen los derechos humanos como un factor sustancial en la pacificación de las relaciones internacionales (Torrejón, 2019), así como una derivación del liberalismo. Juntos, promueven la doctrina de defensa del individuo, que surge para hacer frente a cualquier condición de arbitrariedad que surja del poder político, doctrina que sumada al constitucionalismo propugnan por la división de poderes como garantía de los individuos y para evitar violaciones a sus derechos, bajo la óptica de que éstos son inherentes a la condición humana (Espejel \& Flores, 2014). 
Dentro del continente la Declaración Universal de Derechos Humanos derivó en la creación de la Convención Americana sobre Derechos Humanos, la que a partir del control determina si las normas o actos de un Estado vulneran o no los tratados, esto en el ámbito externo; mientras que, en el ámbito del derecho interno, establece la obligación que tienen todos los Estados y órganos estatales de verificar la aplicación y salvaguarda de los principios y disposiciones, establecidas en dicha convención, en cada caso o actuación (Suárez, 2020).

La Convención Americana de los Derechos Humanos fue suscrita en 1969 y ratificada en 1977 por Ecuador, actos a través de los cuales se comprometió a cumplir con las normas establecidas, así como adecuar su normativa interna de acuerdo con las disposiciones estipuladas en el tratado internacional y la interpretación que le haya dado la Corte Interamericana, so pena de responsabilidad internacional (Cacpata et al., 2020). Es importante acotar que también Ecuador se ha mostrado ampliamente receptivo a los estándares internacionales de Derechos Humanos para la protección de las personas y grupos de atención prioritaria (Israel, 2017).

Entre los principios propugnados por los instrumentos internacionales de protección de Derechos Humanos, se encuentra el principio de favorabilidad. El principio de favorabilidad o de ley posterior más benigna está reconocido en todo el ordenamiento jurídico -con mayor énfasis en sede constitucional y penal-. Este principio es reconocido por la Declaración Universal de los Derechos Humanos (1948), en su artículo 11.2; por el Pacto Internacional de Derechos Civiles y Políticos (1966), en el artículo 15.1 y por la Convención Americana sobre Derechos Humanos (1969), en su artículo 9.

Se aprecia de este modo, que los Derechos Humanos han cobrado una importancia central en el desarrollo de los Estados, más aún, cuando diferentes cuerpos normativos internacionales $y$ regionales se han esforzado por contemplar el mayor catálogo de derechos posible, incluyendo también cuestiones relacionadas con el ámbito procesal penal, donde el principio de favorabilidad constituye un eje.

Muestra de esto es que la Corte Interamericana de Derechos Humanos $(\mathrm{CIDH})$, en la Sentencia por el Caso "Masacre de La Rochela vs Colombia", establece que, a más de los principios de proporcionalidad, en los procesos debe tomarse en cuenta la favorabilidad, en los siguientes términos:

"En cuanto al principio de favorabilidad de una ley anterior debe procurarse su armonización con el principio de proporcionalidad, de manera que no se haga ilusoria la justicia penal. Todos los elementos que incidan en la efectividad de la pena deben responder a un objetivo claramente verificable y ser compatibles con la Convención" (CIDH, 2007, Párr. 196).

Consecuentemente, los principios contenidos en el COIP y en la CRE del 2008 son plenamente compatibles y en particular el de favorabilidad, cumpliendo con el espíritu expresado por la $\mathrm{CIDH}$, tomando en cuenta la enorme gama de actividades que el Estado ejercita en uso del poder punitivo, donde el procesado o sentenciado debe enfrentarse a múltiples formas de "coerción legal con que cuenta el aparato burocrático; de ahí que exista la necesidad imperiosa que el Estado tenga unos límites frente a sus gobernados" (Cabrera Macías, 2016, p. 19).

\section{Desarrollo histórico del principio de favorabilidad en Ecuador}

El devenir histórico-jurídico ecuatoriano al inicio de su independencia como República, tuvo como legado las leyes penales españolas, hasta que en 1837 se promulgó el primer Código Penal nacional. Conforme a los postulados de la época, el Código siguió teniendo una influencia de la Corona española, pero con la caracterización de la inclusión de principios fundamentales e ideas liberales, en especial, el principio de 
legalidad de los delitos, así como de las penas.

En Ecuador, históricamente el principio de favorabilidad se encontraba inserto en el principio de legalidad; así se recoge en los Códigos Penales de 1872, 1906, 1938, 1953, 1960 y 1971, este último, estuvo vigente hasta el 2014.

Por ejemplo, en el Código Penal de 1971, inmediato anterior al COIP, se regulaba de forma implícita al principio de favorabilidad al interior del principio de legalidad en los siguientes términos:

"Nadie puede ser reprimido por un acto que no se halle expresamente declarado infracción por la Ley penal, ni sufrir una pena que no esté en ella establecida.

La infracción ha de ser declarada, y la pena establecida, con anterioridad al acto.

Deja de ser punible un acto si una Ley posterior a su ejecución lo suprime del número de las infracciones; $y$, si ha mediado ya sentencia condenatoria, quedará extinguida la pena, haya o no comenzado a cumplirse.

Si la pena establecida al tiempo de la sentencia difiere de la que regía cuando se cometió la infracción, se aplicará la menos rigurosa.

En general, todas las leyes posteriores sobre los efectos y extinción de las acciones y de las penas se aplicarán en lo que sean favorables a los infractores, aunque exista sentencia ejecutoriada" (art. 2).

Luego, en el año 2008 con la entrada en vigencia de la $C R E$, se recoge en el art. 76, numeral 5 el principio de favorabilidad, como ya se analizó anteriormente, el que posteriormente serviría de base para la posterior redacción del COIP en reemplazo del Código Penal (CP) y del CPP.

Con la promulgación del COIP esta situación cambió, toda vez que dichos principios se separaron, regulados en numerales diferentes. De esta forma, en el artículo 5 de dicho código referente a los principios procesales en el numeral 1 se expresa que: "Legalidad: no hay infracción penal, pena, ni proceso penal sin ley anterior al hecho. Este principio rige incluso cuando la ley penal se remita a otras normas o disposiciones legales para integrarla" (Asamblea Nacional de la República del Ecuador, 2014) y más adelante en el numeral 2 se declara que: "Favorabilidad: en caso de conflicto entre dos normas de la misma materia, que contemplen sanciones diferentes para un mismo hecho, se aplicará la menos rigurosa aun cuando su promulgación sea posterior a la infracción" (Asamblea Nacional de la República del Ecuador, 2014), saldando así una antigua deuda del sistema normativo penal ecuatoriano.

\section{Principio de favorabilidad}

Aunque anteriormente se ha hecho mención al principio de favorabilidad resulta imprescindible un acercamiento epistémico a dicha institución. Para el Diccionario Panhispánico del Español Jurídico (2021), el principio de favorabilidad es un "principio rector de la jurisdicción constitucional que ordena que la Constitución y los derechos fundamentales deben ser interpretados y aplicados de modo que se optimice su máxima efectividad para favorecer al titular del derecho fundamental".

A más de eso, el antes citado diccionario extiende su definición estableciendo que:

"En los casos en que exista conflicto entre normas integrantes del bloque de constitucionalidad, prevalecerá la que sea más favorable al titular del derecho vulnerado. Si una norma infraconstitucional es más favorable para el titular del derecho fundamental que las normas del bloque de constitucionalidad, la primera se aplicará de forma complementaria, de manera tal que, se asegure el máximo nivel de protección. Ninguna disposición de la ley puede ser interpretada en el sentido de limitar o suprimir el goce y ejercicio de los derechos y garantías fundamentales"

(Diccionario 
Panhispánico del Español Jurídico, 2021).

Estas definiciones muestran el pleno carácter constitucional de este principio, que forma parte fundamental de los principios que sirven de base para el debido proceso (Vásconez Valdez, 2016), dado que más allá de su aplicación en el Derecho penal, sirve también como principio rector en otras áreas, como, por ejemplo, en el Derecho Administrativo, así como en el Derecho Tributario, en el caso de la etapa de cobro y en materia de devoluciones de pago en exceso (Rincón Palacio, 2020).

Dada la estrecha relación que existe entre el principio de legalidad y favorabilidad, Paladines et al. (2014), mencionan que el principio de favorabilidad es la consecuencia retroactiva del principio de legalidad, dando como argumento la necesidad de una ley previa que señale el delito y la pena, y la posterior modificación - eliminación de tal ley, conjugándose además los principios de in dubio pro reo y la interpretación in bonam partem. El favor rei contiene al principio de favorabilidad, tal como menciona Bravo Pardo (2017), este principio beneficia a la persona tanto en su calidad de procesada como de condenada.

Para Carrasquilla, citado por Naranjo López (2016), el principio de favorabilidad no es un principio de interpretación legal, sino que sirve como guía para que el prestador de justicia pueda elegir entre la ley más favorable cuando se presente una sucesión de leyes penales, diferentes en el tiempo. Para Piqué (2013), la aplicación del principio de favorabilidad deviene de un análisis político criminal, por medio del cual, resulta ilógico que se mantenga una pena cuando un hecho ya no se considera delito, así como cuando su pena se rebaja, - cuando sus especificidades procesales cambien también y generen una situación más favorable para el procesado o sentenciado.

Por lo expuesto, el principio de favorabilidad y su valoración respecto de las penas, procesos y sentencias que por motivos de política criminal $y$ modificaciones legislativas, varíen, permite ponderar bajo la aplicación del principio pro homine que la persona tanto natural como jurídica se encuentra en una posición superior a la de la ley, encaminando, como establece Olaya Gómez (2016), una protección sobre el sujeto que está siendo objeto de la acción penal, necesitado de una protección jurídica frente a la fuerza abrazadora del Estado.

\section{La favorabilidad como principio del debido proceso}

El debido proceso como derecho continente, alberga en sí una serie de principios y garantías, entre los que se encuentran el de legalidad $y$ el de favorabilidad, tal como se apreció al momento de analizar el art. 76 de la CRE. Su inclusión aborda la protección de derechos subjetivos referentes a los sujetos procesales, en este caso, a la persona procesada o sentenciada, formando parte del catálogo de derechos fundamentales que las convenciones y tratados exigen a los Estados firmantes.

El principio de favorabilidad tiene la versatilidad de poder ser alegado en diversas etapas procesales, así como posterior a la ejecución de la sentencia, toda vez que como establecen los jueces de la Corte Provincial de Imbabura (2015) "el principio de favorabilidad, como expresión del principio de legalidad, y del derecho a seguridad jurídica, debe ser aplicado tanto en lo sustantivo penal, como en lo procesal penal; $y$, en la ejecución de pena". Lo cual es resaltado en la cita de la Corte Provincial de Imbabura al denotar el contenido o alcance del principio de favorabilidad que se resume en tres momentos o materias: a) sustantivo $o$ penal, $b$ ) adjetivo 0 procedimental y c) ejecutivo o penológico.

Eminentemente, el principio de favorabilidad es un principio procesal, pero cobra otras características cuando éste se aplica de manera posterior a la sentencia, amplificando su alcance y, por ende, siendo aún más importante de cara a proteger a los ciudadanos de una aplicación desmedida del poder punitivo del Estado, 
en pro de lograr un proceso debido, apegado a los estándares internacionales.

\section{Procedimiento de acción privada. En el CP y en el COIP (delitos de acción privada en CP y en COIP)}

Antes de centrar el estudio en el ejercicio de la acción penal de carácter privado, es necesario definir qué se entiende por acción penal. Para Manzini, citado por Chávez Peña (2014) "la acción penal tiene siempre por objeto una pretensión punitiva del Estado, derivada de un delito, concreta e hipotéticamente realizable" (p. 11). De este modo, se interpreta que la acción penal es el inicio de la pretensión punitiva del Estado, de su capacidad de aplicar el ius puniendi, entendido este último como la potestad estatal en virtud de la que ciertos hechos pueden ser susceptibles de penas o medidas de seguridad (Bustos Ramírez, 2005). Sin embargo, a la interpretación antes realizada se escapa que, en ciertos casos, la pretensión punitiva no recae en una decisión del Estado de perseguir el delito (fiscalía), sino a la víctima, como es en el caso de los delitos de ejercicio de la acción privada, como se verá más adelante.

Por su parte, dentro de los tipos penales recogidos por los cuerpos punitivos, existe la separación de las infracciones en dos categorías. Por un lado, los delitos, concebidos como "una de las formas en que se manifiesta la infracción jurídica: una de las formas de incumplimiento de los preceptos contenidos en las normas de Derecho" (Bajo Fernández \& Lascuraín Sánchez, 2019, p. 32), y a entender de Cigüela Sola (2020) el delito relaciona al autor con la víctima, así como al autor con el ordenamiento jurídico, lesionándolos a ambos. Por otro lado, las contravenciones, si bien, de igual manera que los delitos, son trasgresiones a los derechos de la parte afectada que lesionan de manera menos grave los intereses sociales y que por esa misma razón, son castigadas con sanciones más leves (Corte Constitucional de Colombia, 1996).
Legalmente, el ejercicio de la acción penal se divide en dos categorías, por un lado, el ejercicio público de la acción privada, que le corresponde de manera única a la fiscalía (Viscarra Armijos, 2010 y Ramón et al., 2016); y, por otro lado, el ejercicio privado de la acción penal, que le asiste de manera exclusiva al afectado, por medio de querella. Esta diferenciación se encuentra recogida actualmente en el COIP, tal como se verá más adelante.

Primigeniamente, el CPP del Ecuador, vigente hasta el año 2014, recogía la distinción entre acción penal pública y privada al establecer que "El ejercicio de la acción pública corresponde exclusivamente al Fiscal, sin necesidad de denuncia previa. El ejercicio de la acción privada corresponde únicamente al ofendido, mediante querella" (Asamblea Nacional de la República del Ecuador, art. 33).

Con respecto a las infracciones que pueden ser tramitadas por medio del ejercicio de la acción penal privada, el articulado del mismo cuerpo normativo señalaba:

"Delitos de acción privada. - Son delitos de acción privada:

a) El estupro perpetrado en una persona mayor de dieciséis años $y$ menor de dieciocho;

b) El rapto de una mujer mayor de dieciséis años y menor de dieciocho, que hubiese consentido en su rapto y seguido voluntariamente al raptor;

c) La injuria calumniosa y la no calumniosa grave;

d) Los daños ocasionados en propiedad privada, excepto el incendio;

e) La usurpación;

f) La muerte de animales domésticos o domesticados (Congreso Nacional de la República del Ecuador, art. 36).

Estos delitos se tramitaban con base a lo señalado en el art. 371 del CPP, ubicados en el Capítulo II que contenía el procedimiento de acción penal privada. 
Posteriormente, en el año 2014 con la entrada en vigencia del COIP, se derogaron tanto el CPP como el CP. El COIP pasó a recoger tanto la parte general como especial del Derecho penal nacional, así como también lo referente a los procedimientos. De este modo, el COIP regula actualmente el ejercicio de la acción penal en los siguientes términos:

"Ejercicio de la acción. - El ejercicio de la acción penal es público y privado.

El ejercicio público de la acción corresponde a la Fiscalía, sin necesidad de denuncia previa.

El ejercicio privado de la acción penal corresponde únicamente a la víctima, mediante querella" (Asamblea Nacional de la República del Ecuador, 2014, art. 410).

Como se puede apreciar, la redacción del COIP tiene variaciones mínimas con respecto al derogado CPP, dejando claramente establecida la diferencia entre el ejercicio público y privado. Al respecto de los delitos que pueden tramitarse por medio del ejercicio privado de la acción penal, el COIP señala:

"Ejercicio privado de la acción penal. Procede el ejercicio privado de la acción en los siguientes delitos:

\section{Calumnia.}

2. Usurpación.

\section{Estupro.}

4. Lesiones que generen incapacidad o enfermedad de hasta treinta días, con excepción de los casos de violencia contra la mujer o miembros del núcleo familiar y delitos de tránsito.

5. Delitos contra animales que forman parte del ámbito para el manejo de la fauna urbana" (Asamblea Nacional de la República del Ecuador, 2014, art. 415).

De lo antes citado, se desprende que algunos delitos que se podían tramitar mediante la acción penal de carácter privado, en la actualidad según el CPP ya no es admitido por esa vía, uno de esos delitos es, precisamente, la injuria no calumniosa. En efecto, en el COIP no aparece la injuria calumniosa como delito de acción privada, de ahí que, como advierte Gallardo Orellana (2016), la injuria dejó de ser tratada como delito para ser recogida como contravención. Esta situación viene en la necesidad de que, respecto de esta infracción penal, al momento de su procesamiento, sea sometida al procedimiento expedito de contravenciones penales.

\section{Los procedimientos contravenciones (¿cuáles eran los delitos aplicables en el CP y en el COIP?)}

En el CPP, en la legislación ecuatoriana se había regulado el procedimiento por el cual se daba trámite a las contravenciones de un modo diferente al que actualmente se prevé para el COIP, toda vez que se diferenciaba el trámite según la clase de contravención, existiendo dos grandes distinciones, por una parte, lo referente al procesamiento por contravenciones de primera clase estipulado en el artículo 397 y por otra, lo señalado para las contravenciones de segunda, tercera y cuarta clase en el artículo 398.

En el primero de estos dos grupos, estaban contenidas las cincuenta y cuatro contravenciones establecidas en el art. 604 del CP. En el segundo grupo, se encontraban aquellas tipificadas en los arts. 605,606 y 607, para un total de 34 contravenciones de segunda clase, 19 de tercera clase y 11 de cuarta clase.

Por su parte, el COIP establece en su artículo 641 que:

"Las contravenciones penales, de tránsito e infracciones y contra los derechos de las personas usuarias y consumidoras y otros agentes del mercado serán susceptibles de procedimiento expedito. El procedimiento se desarrollará en una sola audiencia ante la o el juzgador competente, la cual se regirá por las reglas generales previstas en este 
Código. En la audiencia, la víctima y el denunciado si corresponde, podrán llegar a una conciliación, salvo el caso de violencia contra la mujer o miembros del núcleo familiar. El acuerdo se pondrá en conocimiento de la o el juzgador para que ponga fin al proceso" (Asamblea Nacional de la República del Ecuador, 2014).

Luego, los artículos 642 al 646 establecen reglas específicas para el procedimiento según cada tipo o clase de contravención, ya no señaladas por números o clases (primera, segunda o tercera clase), sino por el bien jurídico contra el que atentan (contra la mujer o miembros del núcleo familiar, contravenciones de tránsito). Dentro del análisis centrado en el artículo 396.1, referente a la contravención de "La persona que, por cualquier medio, profiera expresiones en descrédito o deshonra en contra de otra", el procedimiento a aplicarse es el contenido en el artículo 642.

\section{El delito de injurias calumniosas no graves (en el CP y en el COIP)}

Por su parte, el delito de injurias calumniosas no graves se encontraba tipificado en el articulado del CP, del siguiente modo:

"La injuria es:

Calumniosa, cuando consiste en la falsa imputación de un delito; y,

No calumniosa, cuando consiste en toda otra expresión proferida en descrédito, deshonra o menosprecio de otra persona, o en cualquier acción ejecutada con el mismo objeto" (Congreso Nacional de la República del Ecuador, 1971, art. 489).

Los hechos que constituían injuria no calumniosa tenían dos subcategorías, las graves y las leves, todas establecidas en el art. 419. Asimismo, existen diferentes tipos de injurias no calumniosas, por ejemplo, las tipificadas en los arts. 491 y 492, donde jugaban un papel fundamental las circunstancias de la infracción. Así, en la primera de ellas el lugar público o la presencia de diez o más personas, los medios escritos o impresos, constituyen elementos descriptivos y normativos determinantes en la configuración del tipo de ese entonces. En la segunda de ellas, las injurias no calumniosas son proferidas en privado o ante la presencia de menos de diez personas.

Existe también una modalidad donde el sujeto pasivo del delito es determinado, en el caso de que las injurias no calumniosas sean proferidas a una autoridad, contenida dicha modalidad en el segundo inciso del art. 493.

Con respecto al vigente COIP, este tipo de delito se encuentra tipificado como una contravención, más específicamente como contravención de cuarta clase, al señalar:

"Contravenciones de cuarta clase. - Será sancionada con pena privativa de libertad de quince a treinta días:

1. La persona que, por cualquier medio, profiera expresiones en descrédito o deshonra en contra de otra.

Esta contravención no será punible si las expresiones son recíprocas en el mismo acto (Asamblea Nacional de la República del Ecuador, 2014, art. 396).

Este traslado desde el catálogo de delitos hacia las contravenciones tiene algunas implicaciones que serán analizadas a continuación.

En primer lugar, las penas disminuyen de manera muy significativa; en el caso de las injurias calumniosas contenidas en el CP, las del art. 491 preveían pena de prisión de 6 meses a 2 años; las del art. 492, penas de 1 a 6 meses; y la modalidad contenida en el art. 493, pena de prisión de 6 meses a 2 años. Estos rangos penológicos, comparados con lo que actualmente recoge el COIP, son ampliamente superiores, dado que según el cuerpo normativo vigente la persona que encuadre su conducta al tipo penal señalado en el art. 396 será sancionada con pena privativa de libertad de 15 a 30 días. 
Respecto de la multa, el derogado CP contenía rangos de multas bajos, donde la conducta señalada en el art. 491 preveía una multa de 6 a 25 USD; el art. 492 una multa de 6 a 12 USD y el art. 493, una multa de 6 a 19 USD. Con respecto a esta pena pecuniaria, si bien el art. 396 no contiene una multa específica, el COIP señala en el art. 70 que en todas las infracciones se aplicará además, la pena de multa, según un listado delimitado por la pena correspondiente a la infracción, siendo que para la pena privativa de libertad señalada para el art. 396 (pena privativa) corresponde la multa del $25 \%$ de un salario básico unificado que a la fecha de realización del presente trabajo equivale a 400 USD, por lo que la multa sería de 100 USD.

Con respecto a las especificidades procesales, en cuanto a la forma de procesamiento de la injuria no calumniosa, con base al art. 373 del CPP, comprendida en una audiencia única, con posibilidad de conciliación y con la obligación de dictar sentencia por parte del juzgador en un plazo de cuatro días. Por su parte, el COIP en el art. 642, el trámite de procedimiento para las contravenciones penales, también prevé la posibilidad de conciliación, y la sentencia, según lo establecido en el art. 621 del mismo COIP, se notificará dentro del plazo de diez días.

\section{El principio de favorabilidad frente a la sustanciación de procedimientos diferentes}

Hasta aquí, se ha fundamentado histórica, doctrinal y legalmente las variables favorabilidad e injuria no calumniosa como delito y como contravención, así como y procedimiento privado y contravencional. Con este respaldo, corresponde abordar la problemática planteada al inicio que, motivó el proceso indagatorio.

El nudo crítico de este trabajo se centra en la necesidad de determinar con sustento jurídico, si procede o no la favorabilidad cuando una persona está siendo procesada por una ley anterior y es sentenciada cuando está vigente una nueva ley que contiene un procedimiento diferente, pero mantiene la conducta penal, aunque ha dejado de ser delito y ha pasado a contravención. Así, como se ha dejado indicado, la favorabilidad tiene un contenido sustantivo, adjetivo y ejecutivo, es decir, se aplica al tipo penal, al procedimiento, y a la ejecución de la pena.

En el presente caso, se han modificado con la nueva ley (COIP), el contenido sustantivo o penal (el delito de injurias por la contravención penal), el contenido adjetivo o procedimental (el procedimiento privado por procedimiento expedito de contravención), y el contenido ejecutivo o penológico (la pena del delito por la pena menor de contravención). De ahí que, el presente es uno de los casos que en principio llenaría no solo uno, con el que es suficiente para que proceda la favorabilidad, sino los tres contenidos a los que se aplican el principio de favorabilidad.

Por otro lado, respecto de las clases o formas de favorabilidad, descartando la favorabilidad retroactiva que permite la aplicación favorable de una ley anterior, en el presente caso, corresponde ubicar el tema en el análisis de la favorabilidad ultractiva, pues, ésta permite que se aplique la ley futura más benigna, en este caso la del COIP, que dejó de considerar delito a la injuria para considerarla contravención dotándole de un procedimiento diferente (expedito contravencional) y de una pena menos grave.

Por otra parte, la Disposición Transitoria Primera del COIP, en principio, señala textualmente que: "Los procesos penales, actuaciones y procedimientos de investigación que estén tramitándose cuando entre en vigencia este Código, seguirán sustanciándose de acuerdo con el procedimiento penal anterior hasta su conclusión (...)" (Asamblea Nacional de la República del Ecuador, 2014).

Los presupuestos fácticos, doctrinarios, constitucionales y legales expuestos, permiten una primera aproximación de solución a la cuestión planteada. En este 
sentido, la respuesta sería la negativa de procedencia del principio de favorabilidad, la Disposición Transitoria así parecería advertirlo. De ahí que, en el supuesto traído a colación en este trabajo, no cabría la aplicación del principio de favorabilidad procedimental porque la transitoria así lo establece. Luego, cabe la interrogante cuna disposición transitoria de una ley orgánica está por encima de un mandato constitucional como la favorabilidad?, la respuesta a esta interrogante la contiene la segunda parte de la transcripción de la citada transitoria cuando, además de lo advertido anteriormente, señala que "(...) sin perjuicio del acatamiento de las normas del debido proceso, previstas en la CRE, siempre que la conducta punible esté sancionada en el presente Código" (Asamblea Nacional de la República del Ecuador, 2014).

Entonces, la citada disposición transitoria, pese a que, en principio, sugiera que los procedimientos que al momento de la entrada en vigencia del COIP se encuentren en curso se continúen con su tramitación hasta su conclusión al amparo de la ley anterior; sin embargo, advierte también, que en dicha tramitación o procedimiento se observarán las garantías básicas del debido proceso. $Y$, precisamente, una garantía básica del debido proceso es la favorabilidad señalado en el artículo 76.5 del COIP.

A la luz de lo analizado, la respuesta al hipotético planteado se tornaría entonces positiva, es decir, a favor que en el caso de $A$ se debe aplicar el principio de favorabilidad procedimental, pues, aunque subsista la conducta, la misma dejó de ser delito y pasó a ser contravención con un procedimiento diferente y una sanción más benigna, inclusive. En consecuencia, deberá dejarse insubsistente el proceso anterior e iniciar un nuevo proceso aplicando la favorabilidad sustantiva, procedimental y penológica ultractiva, esto es, la contravención, el proceso expedito y la pena de contravención más favorable. Todo esto en aplicación de lo que establece el artículo 9 de la Convención Americana sobre Derechos Humanos (1969); artículo
76.5 de la CRE; artículos 5.2; 16.2 y Disposición Transitoria Primera del COIP.

\section{CONCLUSIONES}

El principio de favorabilidad tiene rango convencional, constitucional y legal; posee contenido sustantivo, procedimental $y$ ejecutivo; $y$, se presenta retroactiva $y$ ultractivamente. Es un derecho humano fundamental que en Ecuador asoma como un principio autónomo e independiente del principio de legalidad dentro del que normalmente se encuentra insertado en otras legislaciones y en el artículo 9 de la Convención Americana sobre Derechos Humanos.

Con respecto al hipotético planteado que motivó el análisis doctrinal y legal de este trabajo, por cuando la favorabilidad es un principio constitucional debe observárselo cuando como en el caso hipotético analizado, una persona se encuentre enfrentando un proceso penal a la luz de una ley anterior que contiene la misma infracción que la ley posterior que entró en vigencia mientras transcurría el proceso, pero que en la ley posterior (COIP) ya no es delito sino contravención, y además le asigna un procedimiento diferente y una pena menor. Esto en atención a la favorabilidad ultractiva como derecho humano fundamental y como garantía del debido proceso.

\section{REFERENCIAS BIBLIOGRÁFICAS}

Aldana, J., \& Isea, J. (2018). Derechos Humanos y Dignidad Humana. Iustitia Socialis. Revista Arbitrada de Ciencias Jurídicas, 3(4), 8-23.

Bajo-Fernández, M. \& Lascuraín-Sánchez, J. (2019). El Derecho penal: Concepto, en AA. VV, Manual de Introducción al Derecho Penal, pp. 27-45.

Bravo-Pardo, M. (2017). El principio de favorabilidad y su aplicación en el proceso penal, en AA.VV. Boletín 
Institucional, Corte Nacional de Justicia, núm. 31. Disponible en https://www.cortenacional.gob.ec/ $\mathrm{cnj} /$ images/pdf/binstitucional/boleti ncnj031.pdf

Bustos-Ramírez, J. (2005). Obras completas. Derecho Penal. Parte General. Tomo I. Lima: Ara Editores.

Cabrera-Macías, F. (2016). El principio de favorabilidad en el Código Orgánico Integral Penal y su aplicación en los delitos relacionados con el narcotráfico. Tesis de Grado, Universidad Católica Santiago de Guayaquil.

http://repositorio.ucsg.edu.ec/bitst ream/3317/7169/1/T-UCSG-PRE-

JUR-DER-MD-46.pdf

Cacpata, W., Prado, E., Chuico, J., \& Campaña, L. (2020). El control de convencionalidad en Ecuador y su aplicación conforme al control de constitucionalidad. Revista Dilemas Contemporáneos: Educación, Política y Valores, 1(45), 1-27.

Carrión-León, K. (2018). La vulneración del principio de legalidad en el juzgamiento del delito de desaparición forzada "caso Gonzales y otros" no tipificado en el Código penal y tipificado en el art 84 del COIP. (Tesis de maestría). Universidad Católica Santiago de Guayaquil.

http://repositorio.ucsg.edu.ec/bitst ream/3317/12101/1/T-UCSG-POSMDC-184.pdf

Cigüela-Sola, J. (2020). Reconocimiento, delito y pena: de Hegel a Honneth. Polít. Crim., 15(29), 202-229.

Congreso Nacional de la República del Ecuador (1971). Código Penal. Quito. Ecuador.

Corte Provincial de Imbabura. (2015). Penal: Procedimiento Abreviado en Casos de Drgas. Justicia para Todos, 2-3-4.
Chávez Peña, E. M. (2014). La Acción Penal Privada y su implementación en Colombia. Via Iuris, (14), 167-185. Recuperado a partir de https://revistas.libertadores.edu.co /index.php/ViaIuris/article/view/12 0

Diccionario Panhispánico del Español Jurídico. (2021). https://dpej.rae.es/lema/principiode-

favorabilidad\# : : text=Principio\%2 Orector\%20de\%20la\%20jurisdicci $\%$ C3\%B3n,al\%20titular\%20del\%2 Oderecho\%20fundamental

Ecuador. Asamblea Nacional de la República (13 de julio de 2011). Constitución de la República del Ecuador 2008. Registro Oficial 449 (Modificaciones) Quito: CEP. https://www.cec-epn.edu.ec/wpcontent/uploads/2016/03/Constituc ion.pdf

Ecuador. Asamblea Nacional de la República (3 de febrero de 2014). Código Orgánico Integral Penal. Registro Oficial No 180. Quito: CEP.

Espejel, J., \& Flores, M. (2014). Liberalismo, derechos humanos y desarrollo en un orden político democrático. Espacios Públicos, 17(41), 157-176.

González-Navarro, L. (2009). El Principio Constitucional de la Favorabilidad Penal. Revista Jurídica de Colombia.

Hinojosa-Gallo, G. (2021). El principio de favorabilidad en el delito de tráfico ilícito de sustancias catalogadas sujetas a fiscalización, en relación a la reincidencia en el cometimiento del delito. (Tesis de Grado). Pontificia Universidad Católica del Ecuador. https://repositorio.pucesa.edu.ec/b itstream/123456789/3113/3/7728 3.pdf

Israel, C. (2017). Estándares de los derechos de las personas y grupos de atención prioritaria en Ecuador. 
Investiga UTPL, Universidad Técnica Particular de Loja, pp. 174-183.

Jaramillo-Martínez, A. (2016). El principio de favorabilidad $y$ el homicidio inintencional (Maestría en Derecho Penal y Criminología). Universidad Regional Autónoma de los Andes. "UNIANDES". Ecuador.

Naranjo-López, R. (2016). El tráfico ilícito de sustancias sujetas a fiscalización $y$ el principio de favorabilidad del procesado. (Tesis de Grado). Universidad Técnica de Ambato. https://repositorio.uta.edu.ec/bitstr eam/123456789/19951/1/FJCSDE-909.pdf

Olaya-Gómez, Y. (2016). El fenómeno de la lex tertia. Problemas de aplicación en el ordenamiento constitucional colombiano. (Tesis de Grado). Fundación Universitaria LoS Libertadores.

https://repository.libertadores.edu. co/bitstream/handle/11371/804/OI ayaG\%C3\%B3m\%C3\%A9zYuliNath aly.pdf?sequence $=2$ \&isAllowed $=y$

Paladines, J., Brito, M., Pazmiño, E. (2014). Guía de aplicación del principio de favorabilidad para las personas condenadas por delitos de drogas en Ecuador. Defensoría Pública del Ecuador.

https://biblioteca.defensoria.gob.ec /bitstream/37000/977/1/Principio $\% 20$ de\%20favorabilidad.pdf

Piqué, M. (2013). Principio de legalidad y de retroactividad. Buenos Aires: Departamento de Publicaciones de la Facultad de Derecho, U.B.A. http://www.derecho.uba.ar/publica ciones/libros/pdf/la-cadh-y-suproyeccion-en-el-derechoargentino/009-pique-legalidad-yretroactividad-la-cadh-y-suproyeccion-en-el-da.pdf

Ramón Pineda, M. Á., Zambrano Campoverde, J. A., \& Espinoza, E. (2016). El trabajo social desde la orientación de género, una mediación educativa. Atenas, 4(36), 169-183.

Reyes-Ardila, J. (2020). El principio de Favorabilidad frente a los tipos penales en blanco. Bogotá, Colombia.

https://www.researchgate.net/profi le/Juan-Reyes-

66/publication/347935642_El_Princ ipio_de_Favorabilidad_frente_a_los _tipos_penales_en_blanco/links/5f e89cffa6fdccdcb807f275/El-

Principio-de-Favorabilidad-frente-alos-tipos-penales-en-blanco.pdf

Ricoy Pérez, C. L., \& Suárez Cedeño, M. (2021). Prevention of aggressive behaviors from the educational process. Sociedad \& Tecnología, 4(2), 265-281. https://doi.org/10.51247/st.v4i2.1 09

Rincón-Palacio, A. (2020). Principio de favorabilidad en la etapa de cobro y situaciones jurídicas consolidadas en materia devoluciones de pagos en exceso. Revista de Derecho fiscal, diciembre 2020. https://revistas.uexternado.edu.co /index.php/fiscal/article/view/6577 /9251\#info

Sánchez, R. (2018). El impacto de los principios de presunción de inocencia y debido proceso legal en los derechos humanos en México. Revista Prospectiva Jurídica, 9(17), 11-44.

Suárez, H. (2020). La detención preventiva en Colombia a la luz de la Convención Americana sobre Derechos Humanos: Un llamado a la aplicación del Control de Convencionalidad. Revista Cambios y Permanencias, 11(1), 379-409.

Tellez Rodríguez, N. (2020). Constructos de la prevención de la violencia infanto juvenil en el contexto Cubano. Sociedad \& Tecnología, 3(2), 11-26. https://doi.org/10.51247/st.v3i2.6 
3 (Original work published 1 de julio de 2020)

Torrejón, J. (2019). "Las operaciones de paz de las Naciones Unidas y los Derechos Humanos: el caso de la MINURSO en el Sáhara Occidental". Revista de Estudios Internacionales Mediterráneos, 1(28), 43-73.

Vásconez-Valdez, A. (2016). Aplicación del principio de favorabilidad a personas sentenciadas en el extranjero por delitos de tráfico de drogas, que se acogieron a instrumentos internacionales de traslado de personas sentenciadas. (Tesis de Máster), Universidad Andina Simón Bolívar, Sede Ecuador.

Viscarra-Armijos, L. (2010). La mediación en la acción penal privada. (Tesis para la obtención de Diplomado Superior en Derecho Procesal Pena). Universidad de Cuenca. https://dspace.ucuenca.edu.ec/bits tream/123456789/2973/1/td4289. pdf

\section{Normativas Internacionales}

Convención Americana sobre Derechos Humanos, 1969.

Declaración Universal de los Derechos Humanos, 1948.

Pacto Internacional de Derechos Civiles y Políticos, 1966.

\section{Jurisprudencia internacional}

Corte Interamericana de Derechos Humanos (11 de mayo de 2007). Caso "Masacre de La Rochela vs Colombia. Sentencia. https://www.corteidh.or.cr/docs/ca sos/articulos/seriec_163_esp.pdf

Corte Constitucional de Colombia. (16 de octubre de 1996) Sentencia C$542 / 96$

https://www.corteconstitucional.go v.co/relatoria/1996/C-542-

96.htm\#: : text=Las\%20contraven ciones $\% 2$ C $\% 20$ como\%20especie\% 20de,con\%20normas\%20de\%20de recho\%20penal

Limitaciones y estudios futuros: El alcance del estudio es su principal limitación, propia de las investigaciones descriptivas; la que será superada con la realización de estudios de corte analítico.

Reconocimiento: Se reconoce el apoyo brindado por la fiscalía de El Oro y la Universidad Técnica de Machala para el acceso a materiales documentales útiles para la realización del estudio.

Contribución de los coautores: Aunque se trabajó de manera mancomunada en la elaboración y revisión del ensayo cada uno de los coautores tuvo responsabilidades especificas; Figueroa Arévalo, fue en el cargado de la búsqueda, análisis y selección de las sentencias que pudieran servir como referencias al caso objeto de estudio, mientras que Suqui Romero elaboró la base de datos. 